\title{
Association of Socioeconomic Changes due to the COVID-19 Pandemic With Health Outcomes in Patients With Skin Diseases: Cross-Sectional Survey Study
}

Yeye Guo ${ }^{1,2,3}$, MD; Minxue Shen ${ }^{1,2,3,4}$, MD, PhD; Xu Zhang ${ }^{1,2,3}$, PhD; Yi Xiao ${ }^{1,2,3}$, MD, MPH, PhD; Shuang Zhao ${ }^{1,2,3}$, MD, PhD; Mingzhu Yin ${ }^{1,2,3}$, MD, PhD; Wenbo Bu ${ }^{5}, \mathrm{MD}$, PhD; Yan Wang ${ }^{5}$, MD, PhD; Xiang Chen ${ }^{1,2,3}$, MD, PhD; Juan $\mathrm{Su}^{1,2,3}, \mathrm{MD}, \mathrm{PhD}$

\footnotetext{
${ }^{1}$ Department of Dermatology, Xiangya Hospital, Central South University, Changsha, China

${ }^{2}$ National Clinical Research Center for Geriatric Disorders, Xiangya Hospital, Changsha, China

${ }^{3}$ Hunan Engineering Research Center of Skin Health and Disease, Hunan Key Laboratory of Skin Cancer and Psoriasis, Xiangya Hospital, Central South University, Changsha, China

${ }^{4}$ Department of Social Medicine and Health Management, Xiangya School of Public Health, Central South University, Changsha, China

${ }^{5}$ Institute of Dermatology, Chinese Academy of Medical Science and Peking Union Medical College, Nanjing, China
}

\section{Corresponding Author:}

Juan Su, MD, PhD

Department of Dermatology

Xiangya Hospital

Central South University

Xiangya Road \#87

Changsha, 410008

China

Phone: 8673184327377

Email: sujuanderm@csu.edu.cn

\section{Abstract}

Background: The outbreak of COVID-19 has profoundly influenced people's lifestyles; these impacts have varied across subgroups of people. The pandemic-related impacts on the health outcomes of people with dermatological conditions are unknown.

Objective: The aim of this paper was to study the association of COVID-19 pandemic-related impacts with health-related quality of life in patients with skin diseases.

Methods: This was a cross-sectional study among Chinese patients with skin diseases. A self-administered web-based questionnaire was distributed through social media. Demographic and clinical data and pandemic-related impacts (isolation status, income changes, and employment status) were collected. The main outcomes included perceived stress (Visual Analog Scale), symptoms of anxiety (Generalized Anxiety Disorder-7) and depression (9-Item Patient Health Questionnaire), quality of life (Dermatology Life Quality Index), and health utility mapping based on the EQ-5D-3L descriptive system. Multivariable logistic regression was used to investigate the associations.

Results: A total of 506 patients with skin diseases completed the survey. The mean age of the patients was 33.5 years (SD 14.0), and $217 / 506$ patients (42.9\%) were male. Among the 506 respondents, $128(25.3 \%)$ were quarantined, $102(20.2 \%)$ reported unemployment, and 317 (62.6\%) reported decrease or loss of income since the pandemic. The pandemic-related impacts were significantly associated with impaired mental well-being and quality of life with different effects. Unemployment and complete loss of income were associated with the highest risks of adverse outcomes, with increases of $110 \%$ to $162 \%$ in the prevalence of anxiety, depression, and impaired quality of life.

Conclusions: Isolation, income loss, and unemployment are associated with impaired health-related quality of life in patients with skin diseases during the COVID-19 pandemic.

(J Med Internet Res 2020;22(9):e22288) doi: 10.2196/22288 


\section{KEYWORDS}

skin diseases; coronavirus disease 2019; unemployment; quality of life; web-based; survey; dermatology; COVID-19; lifestyle; impact; outcome; isolation

\section{Introduction}

The outbreak of COVID-19 has resulted in the infection of over $4,000,000$ people in 216 countries and regions worldwide as of May 17, 2020 [1]. A global response of social distancing was undertaken to control the transmission of the disease, and people started voluntarily isolating themselves at home. The Chinese government suggested that the public quarantine at home in January 2020. In the following months, many other countries, such as the United Kingdom, Italy, and the United States, called for self-isolation [2,3]. These actions effectively reduced the rapid spread of the disease but unavoidably had a substantial impact on the global economy. During this time, great socioeconomic changes occurred, such as reduced workforce and increasing unemployment [4]. According to data from the US Labor Department, the unemployment rate soared to $14.7 \%$ in April 2020 [5]. According to a survey in the United States, up to $43.4 \%$ of adults reported that their families suffered a job or income loss during the pandemic [6].

In addition to the socioeconomic implications of the pandemic, the health status of the public is a critical issue that should not be ignored. It is well-known that isolation itself is a risk factor for many mental health issues, including suicide and self-harm [2]. Therefore, long-term isolation in conjunction with loss of employment or income may produce adverse effects on individuals' mental well-being and quality of life [7], especially for people who have chronic diseases.

Skin disorders are among the most prevalent human diseases; they affect $30 \%$ to $70 \%$ of individuals [8]. Skin diseases may cause disfigurement and cutaneous symptoms, and they may result in considerable discomfort and disability. Although most skin diseases are not life-threatening, many of these diseases, such as psoriasis and eczema, are chronic and recurrent. Additionally, itch and fatigue are common symptoms reported by patients with skin diseases, and some also report experiencing pain [9]. Consequently, skin diseases cause not only physical but also psychological discomfort as well as impaired quality of life [10]. Additionally, skin diseases create financial burdens on families and society. A study in the United States suggested that skin diseases cost an estimated $\$ 39.3$ billion per year [11]. As a result, isolation, unemployment, and loss of income related to the COVID-19 pandemic may place patients with skin diseases at additional health risk.

To date, no study has been published regarding the potential influence of socioeconomic changes on the health status of patients with skin diseases during the COVID-19 pandemic. In this study, we investigated the association of COVID-19-related impacts, including isolation, unemployment, and income loss, with health-related quality of life in patients with skin diseases, including perceived stress, symptoms of anxiety and depression, and quality of life during the pandemic.

\section{Methods}

\section{Study Design and Participants}

We performed a cross-sectional study among Chinese patients with skin diseases. A web-based survey link was created and posted on social media platforms (WeChat groups and teledermatology platforms) to facilitate the collection of questionnaires. To avoid repeat submissions, each single IP address was allowed to submit answers only one time. Completion of all questions was required before submission of the questionnaire. All the participants were allowed to quit at any time if any question made them feel uncomfortable. The survey was conducted from April 15 to 27, 2020. The study was reviewed and approved by the institutional research ethics board of Xiangya Hospital, Central South University (Changsha, China; approval number: 202002024). Electronic informed consent was collected from all participants.

\section{Exposure Variables}

Three exposure variables were defined. Outdoor activity restriction was determined by a single question: "During the last month, what measures did you take for isolation?" with the following four responses: "I was not isolated, and my outdoor activity was unaffected," "I was not isolated, but my outdoor activity was partly affected," "I was isolated at home and receiving medical observation," and "I was quarantined in hospital and receiving medical observation or treatment." Because only one patient reported having COVID-19 and being quarantined in hospital, patients who were quarantined at home or in the hospital were combined into one group in the analysis.

The employment status was determined by a single question: "How is your employment status since the epidemic?" with the following responses: "I am unemployed since the epidemic" and "My employment status has been unaffected since the epidemic."

Income change was measured by a single question: "Has your monthly income changed since the epidemic of COVID-19?" with the following responses: "I have completely lost my income," "My monthly income has decreased," "My monthly income has been unaffected," and "My monthly income has increased." Because only two patients reported increased income, they were categorized in the "unaffected" group in the analysis.

\section{Patient-Reported Outcomes}

The primary outcomes were perceived stress and depression and anxiety, which were measured using some short, simple scales to minimize respondent burden.

The Visual Analog Scale (VAS) was used to assess perceived stress during the past two weeks. The area under the receiver operating characteristic curve of the VAS was 0.9 to 0.93 , with a cutoff of 6.8 to 7.2 according to the Perceived Stress Scale-14 
(PSS-14) [12,13]. Here, we used a cutoff of $\geq 7$ to define significant perceived stress.

The Generalized Anxiety Disorder-7 (GAD-7) and the 9-item Patient Health Questionnaire (PHQ-9) were applied to examine the symptoms of anxiety and depression during the past two weeks. The cutoff point for both scales was $\geq 8[14,15]$. The Cronbach $\alpha$ coefficients of the GAD-7 and PHQ-9 in our sample were .93 and .89 , respectively.

The Dermatology Life Quality Index (DLQI) was used to assess the respondents' quality of life during the past two weeks. The cutoff point was $\geq 10$ in our study [16]. The Cronbach $\alpha$ coefficient of the DLQI in our sample was .76. Health utility was mapped using the generic tool EQ-5D-3L according to the method proposed by Liu et al [17].

\section{Covariates}

Demographic and clinical data of the individuals were collected and analyzed as covariates, including gender (male or female), age, marital status (unmarried, married, divorced, or widowed), educational level (primary school and below, middle school, high school, or college and above), annual income ( $<¥ 10,000$, $¥ 10,000$ to $¥ 49,999$, $¥ 50,000$ to $¥ 99,999$, or $\geq ¥ 100,000$, equivalent to US $\$ 1,464.47, \$ 1,464.4$ to $\$ 7,322.21, \$ 7,322.36$ to $\$ 14,644.57$, or $\geq \$ 14,644.72$ ), type of skin diseases (infectious skin diseases, papulosquamous disorders, allergic skin diseases, disorders of appendages, pigmentary disorders, skin tumors), course of disease ( $<1$ year, 1 to 5 years, 6 to 10 years, $>10$ years), adherence to treatment, and use of health care services.

\section{Statistical Analyses}

The data were exported from the web-based survey system and analyzed with $\mathrm{R}$ version 3.4 (R Project). Continuous variables with normal distribution were expressed as mean (SD) and compared with analysis of variance. Continuous data with skewed distributions were presented as median (IQR) and compared with the Wilcoxon rank sum test. Categorical variables were summarized as counts (percentages) and compared using the chi-square test or Fisher exact test. The interaction effects of the exposure variables were examined. The effect sizes of the associations were presented as adjusted odds ratios (aORs) and $95 \%$ CIs. A $P$ value $<.05$ was considered statistically significant. Reporting of the results followed the Strengthening the Reporting of Observational studies in Epidemiology (STROBE) guidelines.

\section{Data Accessibility}

Data are available upon request from JS.

\section{Results}

In total, 506 valid questionnaires were collected and analyzed. No patient reported confirmed infection with COVID-19. The average time to complete the survey was 7.2 minutes (IQR 4.1-8.2). The mean age of the patients was 33.5 years (SD 14.0), and $217 / 506$ patients (42.9\%) were men. As shown in Table 1, allergic skin diseases are the most commonly reported type (103/506, 20.4\%), followed by papulosquamous disorders $(58 / 506,11.5 \%)$, infectious skin diseases $(57 / 506,11.3 \%)$, disorders of appendages $(46 / 506,9.1 \%)$, pigmentary disorders $(38 / 506,7.5 \%)$, hair disorders $(38 / 506,7.1 \%)$, and skin tumors (30/506, 5.9\%).

Of the 506 participants, $252(49.8 \%)$ reported unaffected outdoor activity, $126(24.9 \%)$ reported partly restricted outdoor activity, and $128(25.3 \%)$ reported isolation. As shown in Table 2, outdoor activity restriction was significantly associated with anxiety, depression, and impaired quality of life (all $P<.05$ ). A total of 102/506 patients (20.2\%) reported unemployment, and approximately two-thirds of the participants $(317 / 506,62.6 \%)$ experienced decrease or loss of income during the pandemic. Both decreased income and unemployment were significantly associated with perceived stress, symptoms of anxiety and depression, and impaired quality of life (all $P<.05$ ). 
Table 1. Characteristics of the participants $(\mathrm{N}=506)$.

\begin{tabular}{|c|c|}
\hline Characteristic & Value \\
\hline Age (years), mean (SD) & $33.5(14.0)$ \\
\hline \multicolumn{2}{|l|}{ Gender, n (\%) } \\
\hline Male & $217(42.9)$ \\
\hline Female & $289(57.1)$ \\
\hline \multicolumn{2}{|l|}{ Marital status, n (\%) } \\
\hline Unmarried & $189(37.4)$ \\
\hline Married & $291(57.5)$ \\
\hline Widowed & $22(4.3)$ \\
\hline Divorced & $4(0.8)$ \\
\hline \multicolumn{2}{|l|}{ Educational level, n (\%) } \\
\hline Primary school and below & $49(9.7)$ \\
\hline Middle school & $69(13.6)$ \\
\hline High school & $82(16.2)$ \\
\hline College and above & $306(60.5)$ \\
\hline \multicolumn{2}{|l|}{ Income $(¥){ }^{\mathrm{a}}, \mathbf{n}(\%)$} \\
\hline$<10,000$ & $155(30.6)$ \\
\hline $10,000-49,999$ & $132(26.1)$ \\
\hline $50,000-99,999$ & $122(24.1)$ \\
\hline$\geq 100,000$ & $97(19.2)$ \\
\hline \multicolumn{2}{|l|}{ Skin disease, n (\%) } \\
\hline Infectious skin diseases & $57(11.3)$ \\
\hline Papulosquamous disorders & $58(11.5)$ \\
\hline Allergic skin diseases & $103(20.4)$ \\
\hline Disorders of appendages & $46(9.1)$ \\
\hline Disorders of hairs & $36(7.1)$ \\
\hline Pigmentary disorders & $38(7.5)$ \\
\hline Skin tumors & $30(5.9)$ \\
\hline Other & $189(37.4)$ \\
\hline \multicolumn{2}{|l|}{ Course of disease (years), n (\%) } \\
\hline$<1$ & $202(39.9)$ \\
\hline $1-5$ & $165(32.6)$ \\
\hline $6-10$ & $57(11.3)$ \\
\hline$>10$ & $82(16.2)$ \\
\hline \multicolumn{2}{|l|}{ Isolation, n (\%) } \\
\hline Outdoor activity unrestricted & $252(49.8)$ \\
\hline Outdoor activity partly restricted & $126(24.9)$ \\
\hline Isolated at home or in hospital & $128(25.3)$ \\
\hline \multicolumn{2}{|l|}{ Loss of income, $n(\%)$} \\
\hline Unaffected & $189(37.4)$ \\
\hline Reduced & $208(41.1)$ \\
\hline Completely lost & $109(21.5)$ \\
\hline Adherence to treatment, $n(\%)$ & \\
\hline
\end{tabular}




\begin{tabular}{cl}
\hline Characteristic & Value \\
\hline Adherent to treatment & $121(23.9)$ \\
No treatment prescribed & $210(41.5)$ \\
Not adherent to treatment & $175(34.6)$ \\
Use of health care services, $\mathbf{n}(\boldsymbol{\%})$ & \\
Visited a physician in hospital & $126(24.9)$ \\
Consulted a doctor remotely & $92(18.2)$ \\
\hline
\end{tabular}

${ }^{\mathrm{a}} 1 ¥=\mathrm{US} \$ 0.15$.

Table 2. Associations of epidemic-related impacts with patient-reported outcome scores of skin diseases ( $\mathrm{N}=506)$.

\begin{tabular}{|c|c|c|c|c|c|c|c|c|c|c|}
\hline \multirow[t]{2}{*}{ Exposure group } & \multicolumn{2}{|l|}{ Stress VAS ${ }^{\mathrm{a}}$} & \multicolumn{2}{|l|}{ PHQ-9 ${ }^{\mathrm{b}}$} & \multicolumn{2}{|l|}{ GAD- $7^{\mathrm{c}}$} & \multicolumn{2}{|l|}{ DLQI $^{\mathrm{d}}$} & \multicolumn{2}{|c|}{ Health utility } \\
\hline & Mean SE & $P$ value & Mean SE & $P$ value & Mean SE & $P$ value & Mean SE & $P$ value & Mean SE & $P$ value \\
\hline \multicolumn{11}{|l|}{ Isolation } \\
\hline Unaffected & $4.05(0.18)$ & $\operatorname{Ref}^{e}$ & $4.56(0.30)$ & Ref & $3.31(0.26)$ & Ref & $5.47(0.41)$ & Ref & $0.96(0.01)$ & Ref \\
\hline Restricted & $4.56(0.26)$ & .10 & $6.33(0.42)$ & $<.001$ & $4.97(0.37)$ & .001 & $6.13(0.58)$ & .35 & $0.93(0.01)$ & .02 \\
\hline Isolated & $4.38(0.25)$ & .30 & $5.77(0.42)$ & .02 & $4.20(0.37)$ & .049 & $7.11(0.58)$ & .02 & $0.93(0.01)$ & .02 \\
\hline \multicolumn{11}{|l|}{ Loss of income } \\
\hline Unaffected & $3.23(0.20)$ & Ref & $4.17(0.34)$ & Ref & $3.19(0.30)$ & Ref & $4.85(0.47)$ & Ref & $0.96(0.01)$ & Ref \\
\hline Reduced & $4.54(0.19)$ & $<.001$ & $5.77(0.32)$ & .001 & $4.19(0.29)$ & .02 & $6.18(0.45)$ & .04 & $0.94(0.01)$ & .051 \\
\hline Completely lost & $5.50(0.26)$ & $<.001$ & $6.39(0.45)$ & $<.001$ & $4.79(0.40)$ & .002 & $7.87(0.62)$ & $<.001$ & $0.92(0.01)$ & $<.001$ \\
\hline \multicolumn{11}{|l|}{ Unemployment } \\
\hline Unaffected & $3.91(0.14)$ & Ref & $4.84(0.23)$ & Ref & $3.60(0.21)$ & Ref & $5.28(0.32)$ & Ref & $0.95(0.00)$ & Ref \\
\hline Unemployed & $5.64(0.28)$ & $<.001$ & $7.15(0.46)$ & $<.001$ & $5.30(0.41)$ & $<.001$ & $9.10(0.63)$ & $<.001$ & $0.91(0.01)$ & $<.001$ \\
\hline \multicolumn{11}{|c|}{ Adherence to treatment } \\
\hline Adherent & $4.75(0.26)$ & Ref & $5.64(0.43)$ & Ref & $3.59(0.38)$ & Ref & $6.24(0.58)$ & Ref & $0.93(0.01)$ & Ref \\
\hline $\begin{array}{l}\text { No treatment } \\
\text { needed }\end{array}$ & $3.94(0.20)$ & .01 & $4.41(0.32)$ & .02 & $3.30(0.29)$ & .54 & $4.12(0.44)$ & $<.001$ & $0.97(0.01)$ & $<.001$ \\
\hline Nonadherent & $4.30(0.22)$ & .18 & $6.14(0.36)$ & .37 & $4.97(0.31)$ & .005 & $8.23(0.48)$ & .008 & $0.93(0.01)$ & .75 \\
\hline
\end{tabular}

${ }^{\mathrm{a}}$ VAS: Visual Analog Scale.

${ }^{\mathrm{b}}$ PHQ-9: Patient Health Questionnaire-9.

${ }^{\mathrm{c}}$ GAD-7: Generalized Anxiety Disorder-7.

${ }^{\mathrm{d}}$ DLQI: Dermatology Life Quality Index.

${ }^{\mathrm{e}}$ Ref: reference group.

We further categorized the scale scores by clinically relevant cutoffs and performed a series of logistic regression models with adjustments. As shown in Table 3, outdoor activity restriction was significantly associated with increased symptoms of depression (aOR 1.36-1.81) and anxiety (aOR 1.39-2.20) as well as impaired quality of life (aOR 1.22-1.78) in a dose-dependent manner (quarantined > partly restricted compared with unrestricted); however, it was not significantly associated with stress. Loss of income was correlated with stress (aOR 1.59-4.05), depression (aOR 2.56-2.56), anxiety (aOR 1.64-2.48), and impaired quality of life (aOR 1.27-2.62) in a dose-dependent manner (loss of income > reduced income compared with unaffected income). Similarly, unemployment was significantly associated with adverse outcomes, including perceived stress, depression, anxiety, and impaired quality of life. 
Table 3. Associations of epidemic-related impacts with patient-reported outcomes of skin diseases $(\mathrm{N}=506)$.

\begin{tabular}{|c|c|c|c|c|c|c|c|c|c|c|c|c|}
\hline \multirow[t]{2}{*}{ Exposure group } & \multicolumn{3}{|c|}{$\begin{array}{l}\text { Perceived stress } \\
\left(\mathrm{VAS}^{\mathrm{a}} \geq 7\right)\end{array}$} & \multicolumn{3}{|c|}{$\begin{array}{l}\text { Depression } \\
\left(\text { PHQ- } 9^{\text {b }} \geq 8\right)\end{array}$} & \multicolumn{3}{|c|}{$\begin{array}{l}\text { Anxiety } \\
\left(\mathrm{GAD}-7^{\mathrm{c}} \geq 8\right)\end{array}$} & \multicolumn{3}{|c|}{$\begin{array}{l}\text { Impaired quality of life } \\
\left(\mathrm{DLQI}^{\mathrm{d}} \geq 10\right)\end{array}$} \\
\hline & $\mathrm{aOR}^{\mathrm{e}, \mathrm{f}}$ & $95 \% \mathrm{CI}$ & $P$ value & $\mathrm{aOR}$ & $95 \% \mathrm{CI}$ & $P$ value & $\mathrm{aOR}$ & $95 \% \mathrm{CI}$ & $P$ value & $\mathrm{aOR}$ & $95 \% \mathrm{CI}$ & $P$ value \\
\hline \multicolumn{13}{|l|}{ Isolation } \\
\hline Unaffected & $\operatorname{Ref}^{g}$ & $\mathrm{~N} / \mathrm{A}^{\mathrm{h}}$ & N/A & Ref & N/A & N/A & Ref & N/A & N/A & Ref & N/A & N/A \\
\hline Restricted & 0.90 & $\begin{array}{l}0.52- \\
1.56\end{array}$ & .71 & 1.36 & $\begin{array}{l}0.84- \\
2.21\end{array}$ & .21 & 1.39 & $\begin{array}{l}0.73- \\
2.64\end{array}$ & .31 & 1.22 & $\begin{array}{l}0.70- \\
2.12\end{array}$ & .48 \\
\hline Isolated & 1.02 & $\begin{array}{l}0.59- \\
1.77\end{array}$ & .93 & 1.81 & $\begin{array}{l}1.13- \\
2.89\end{array}$ & .013 & 2.20 & $\begin{array}{l}1.23- \\
3.96\end{array}$ & .008 & 1.78 & $\begin{array}{l}1.05- \\
3.01\end{array}$ & .03 \\
\hline \multicolumn{13}{|l|}{ Loss of income } \\
\hline Unaffected & Ref & N/A & N/A & Ref & N/A & N/A & Ref & N/A & N/A & Ref & N/A & N/A \\
\hline Reduced & 1.59 & $\begin{array}{l}0.91- \\
2.79\end{array}$ & .10 & 2.22 & $\begin{array}{l}1.38- \\
3.57\end{array}$ & .001 & 1.64 & $\begin{array}{l}0.88- \\
3.06\end{array}$ & .12 & 1.27 & $\begin{array}{l}0.73- \\
2.20\end{array}$ & .40 \\
\hline Complete loss & 4.05 & $\begin{array}{l}2.13- \\
7.72\end{array}$ & $<.001$ & 2.56 & $\begin{array}{l}1.43- \\
4.58\end{array}$ & .002 & 2.48 & $\begin{array}{l}1.19- \\
5.13\end{array}$ & .02 & 2.62 & $\begin{array}{l}1.40- \\
4.92\end{array}$ & .003 \\
\hline \multicolumn{13}{|l|}{ Unemployment } \\
\hline Unaffected & Ref & N/A & N/A & Ref & N/A & N/A & Ref & N/A & N/A & Ref & N/A & N/A \\
\hline Unemployed & 2.41 & $\begin{array}{l}1.42- \\
4.08\end{array}$ & .001 & 2.11 & $\begin{array}{l}1.30- \\
3.43\end{array}$ & .003 & 2.60 & $\begin{array}{l}1.45- \\
4.65\end{array}$ & .001 & 2.59 & $\begin{array}{l}1.54- \\
4.35\end{array}$ & $<.001$ \\
\hline \multicolumn{13}{|c|}{ Adherence to treatment } \\
\hline Adherent & Ref & N/A & N/A & Ref & N/A & N/A & Ref & N/A & N/A & Ref & N/A & N/A \\
\hline $\begin{array}{l}\text { No treatment } \\
\text { needed }\end{array}$ & 0.81 & 0.461 .41 & .45 & 0.86 & $\begin{array}{l}0.52- \\
1.44\end{array}$ & .26 & 0.66 & $\begin{array}{l}0.33- \\
1.29\end{array}$ & .22 & 0.58 & $\begin{array}{l}0.32- \\
1.04\end{array}$ & .07 \\
\hline Nonadherent & 0.81 & $\begin{array}{l}0.46- \\
1.42\end{array}$ & .46 & 1.39 & $\begin{array}{l}0.84- \\
2.31\end{array}$ & .68 & 1.39 & $\begin{array}{l}0.75- \\
2.58\end{array}$ & 0.297 & 1.35 & $\begin{array}{l}0.78- \\
2.33\end{array}$ & .29 \\
\hline
\end{tabular}

${ }^{\mathrm{a}}$ VAS: Visual Analog Scale.

${ }^{b}$ PHQ-9: Patient Health Questionnaire-9.

${ }^{\mathrm{c} G A D}$-7: Generalized Anxiety Disorder-7.

${ }^{\mathrm{d}}$ DLQI: Dermatology Life Quality Index.

$\mathrm{e}_{\mathrm{aOR}}$ : adjusted odds ratio.

${ }^{\mathrm{f}}$ Adjusted for age, gender, income, and educational level.

${ }^{\mathrm{g}}$ Ref: reference group.

${ }^{\mathrm{h}} \mathrm{N} / \mathrm{A}$ : not applicable.

Among the 506 participants, 175 (34.6\%) reported nonadherence to treatment. The reasons for nonadherence included limited accessibility to health care due to isolation $(n=273,53.9 \%)$, voluntarily stopping a prescription $(n=106,20.9 \%)$, forgetting to take medicine $(\mathrm{n}=71,14.0 \%)$, and limited accessibility to medications $(n=56,11.1 \%)$. However, nonadherence was not significantly associated with adverse outcomes (Tables 2 and 3).

\section{Discussion}

\section{Principal Findings}

In the current study, we investigated the association of the impact of the COVID-19 pandemic with health-related quality of life in Chinese patients with skin diseases through a web-based survey. Our results indicated that over half of the respondents experienced quarantine and loss of income during the pandemic. These patients reported higher levels of perceived stress, increased symptoms of anxiety and depression, and impaired quality of life. To the best of our knowledge, this is the first impact analysis of the COVID-19 pandemic in patients with skin diseases. Our study reveals considerable proportions of impaired quality of life and mental well-being in these patients. Telemedicine, mental health intervention, and social support are needed for patients with skin diseases during this particular period.

Studies have indicated increases in mental health issues among medical staff [18] and patients with chronic diseases [19] since the outbreak of COVID-19. However, there is little research regarding the impact of the pandemic on patients with skin diseases. Here, we identified isolation, unemployment, and loss of income as significant risk factors for poor mental well-being and quality of life in patients with skin diseases. 
Public health efforts to prevent the spread of COVID-19 are having a growing impact on the global economy. A considerable number of individuals are losing their jobs, at least temporarily [20]. It has been estimated that the worldwide unemployment rate will increase from $4.936 \%$ to $5.644 \%$ due to the COVID-19 pandemic [2]. According to our data, over $20 \%$ of participants $(109 / 506,21.5 \%)$ became unemployed, which is notably higher than the reported unemployment rate. Additionally, 208 of the 506 patients $(41.1 \%)$ experienced reduced income even though they were not unemployed; this also resulted in impaired mental health and quality of life. In addition to the financial impacts, job loss can disrupt health insurance coverage [21]. Although many countries have provided free testing or even treatment for COVID-19, medical costs for other conditions related to the pandemic are generally not covered by these reimbursement policies.

It should be noted that $65 \%$ of the respondents' nonadherence to treatment was related to limited accessibility to health institutions or medications based on our observations. Since the pandemic, many hospitals and health care institutions have temporarily closed their outpatient services to avoid nosocomial infection and better allocate health care resources, which has created unique challenges to health care delivery at present [22]. A previous study described the possibility of using telemedicine in disasters or public health emergencies [23]. Most developed areas have been using telemedicine not only for physical health care, but also for mental health services [24]. However, it is difficult for patients in rural areas who lack internet services and smartphones to use remote health care. Current telemedicine programs in China and some countries enable consultation services but do not provide medication delivery services; this could eventually cause nonadherence to treatment due to lack of medication.

\section{Limitations}

Our study has some limitations. First, the survey was web-based, with low representativeness due to nonprobability sampling. Second, the exposure and outcome variables were self-reported, and recall bias may have been introduced. Third, some relevant outcomes such as sleep quality were not included in our study because a heavy survey burden may lead to fewer responses and lower accuracy. Last, the survey was conducted among Chinese patients and may not fully represent all patients in areas beyond China due to cultural differences as well as variations in reimbursement policies and social systems.

\section{Conclusions}

Taken together, our findings indicate that pandemic-related impacts are associated with adverse patient-reported outcomes of skin diseases. Early and timely mental health intervention, telemedicine, and health education are needed for these patients. Preferably, social support and reimbursement policies will further help patients under heavy financial burdens endure this difficult period.

\section{Acknowledgments}

This work was supported by the National Natural Science Foundation of China $(62041208,81974478)$, the Ministry of Science and Technology of the People's Republic of China (2016YFC0900802), the Emergency Project of Prevention and Control for COVID-19 of Central South University (502701002), and the Department of Science and Technology of Hunan Province (2018SK2086, 2018SK2092). We would like to thank all the melanoma patients who participated in our study for their support and assistance in the web-based survey. Particularly, we want to express our high regard to all the health practitioners and volunteers for their dedication in the fight against COVID-19.

\section{Authors' Contributions}

Yeye Guo and Minxue Shen contributed equally as first authors. Xiang Chen and Juan Su contributed equally as last authors.

\section{Conflicts of Interest}

None declared.

\section{References}

1. Coronavirus disease (COVID-19) pandemic. World Health Organization. URL: $\underline{\text { https://www.who.int/emergencies/diseases/ }}$ novel-coronavirus-2019 [accessed 2020-05-21]

2. Kawohl W, Nordt C. COVID-19, unemployment, and suicide. Lancet Psychiatry 2020 May;7(5):389-390 [FREE Full text] [doi: 10.1016/S2215-0366(20)30141-3] [Medline: $\underline{32353269}$ ]

3. Day M. Covid-19: identifying and isolating asymptomatic people helped eliminate virus in Italian village. BMJ 2020 Mar 23;368:m1165. [doi: 10.1136/bmj.m1165] [Medline: $\underline{\text { 32205334] }}$

4. Nicola M, Alsafi Z, Sohrabi C, Kerwan A, Al-Jabir A, Iosifidis C, et al. The socio-economic implications of the coronavirus pandemic (COVID-19): A review. Int J Surg 2020 Jun;78:185-193 [FREE Full text] [doi: 10.1016/j.ijsu.2020.04.018] [Medline: $\underline{\text { 32305533] }}$

5. Long H, Van Dam A. U.S. unemployment rate soars to 14.7 percent, the worst since the Depression era. Washington Post. 2020 May 08. URL: https://www.washingtonpost.com/business/2020/05/08/april-2020-jobs-report/ [accessed 2020-09-01]

6. Acs G, Karpman M. Employment, Income, and Unemployment Insurance during the COVID-19 Pandemic. Urban Institute. 2020 Jun 30. URL: https://www.urban.org/research/publication/ employment-income-and-unemployment-insurance-during-covid-19-pandemic [accessed 2020-09-01] 
7. Alradhawi M, Shubber N, Sheppard J, Ali Y. Effects of the COVID-19 pandemic on mental well-being amongst individuals in society- A letter to the editor on "The socio-economic implications of the coronavirus and COVID-19 pandemic: A review". Int J Surg 2020 Jun;78:147-148 [FREE Full text] [doi: 10.1016/j.ijsu.2020.04.070] [Medline: $\underline{32380230]}$

8. Hay RJ, Johns NE, Williams HC, Bolliger IW, Dellavalle RP, Margolis DJ, et al. The global burden of skin disease in 2010: an analysis of the prevalence and impact of skin conditions. J Invest Dermatol 2014 Jun;134(6):1527-1534 [FREE Full text] [doi: 10.1038/jid.2013.446] [Medline: 24166134]

9. Verhoeven EWM, Kraaimaat FW, van de Kerkhof PCM, van Weel C, Duller P, van der Valk PGM, et al. Prevalence of physical symptoms of itch, pain and fatigue in patients with skin diseases in general practice. Br J Dermatol 2007 Jun;156(6):1346-1349. [doi: 10.1111/j.1365-2133.2007.07916.x] [Medline: 17535233 ]

10. Basra MKA, Shahrukh M. Burden of skin diseases. Expert Rev Pharmacoecon Outcomes Res 2009 Jun;9(3):271-283. [doi: 10.1586/erp.09.23] [Medline: 19527100$]$

11. Bickers DR, Lim HW, Margolis D, Weinstock MA, Goodman C, Faulkner E, American Academy of Dermatology Association, Society for Investigative Dermatology. The burden of skin diseases: 2004 a joint project of the American Academy of Dermatology Association and the Society for Investigative Dermatology. J Am Acad Dermatol 2006 Sep;55(3):490-500. [doi: 10.1016/j.jaad.2006.05.048] [Medline: 16908356]

12. Dutheil F, Pereira B, Moustafa F, Naughton G, Lesage F, Lambert C. At-risk and intervention thresholds of occupational stress using a visual analogue scale. PLoS One 2017;12(6):e0178948 [FREE Full text] [doi: 10.1371/journal.pone.0178948] [Medline: 28586383]

13. Lesage FX, Berjot S. Validity of occupational stress assessment using a visual analogue scale. Occup Med (Lond) 2011 Sep;61(6):434-436. [doi: 10.1093/occmed/kqr037] [Medline: 21505089]

14. Liu Z, Yu Y, Hu M, Liu H, Zhou L, Xiao S. PHQ-9 and PHQ-2 for Screening Depression in Chinese Rural Elderly. PLoS One 2016;11(3):e0151042 [FREE Full text] [doi: 10.1371/journal.pone.0151042] [Medline: 26978264]

15. Plummer F, Manea L, Trepel D, McMillan D. Screening for anxiety disorders with the GAD-7 and GAD-2: a systematic review and diagnostic metaanalysis. Gen Hosp Psychiatry 2016;39:24-31. [doi: 10.1016/j.genhosppsych.2015.11.005] [Medline: 26719105]

16. Finlay AY, Khan GK. Dermatology Life Quality Index (DLQI)--a simple practical measure for routine clinical use. Clin Exp Dermatol 1994 May;19(3):210-216. [doi: 10.1111/j.1365-2230.1994.tb01167.x] [Medline: 8033378]

17. Liu GG, Wu H, Li M, Gao C, Luo N. Chinese time trade-off values for EQ-5D health states. Value Health 2014 Jul;17(5):597-604 [FREE Full text] [doi: 10.1016/j.jval.2014.05.007] [Medline: 25128053]

18. Chen Q, Liang M, Li Y, Guo J, Fei D, Wang L, et al. Mental health care for medical staff in China during the COVID-19 outbreak. Lancet Psychiat 2020 Apr;7(4):e15-e16. [doi: 10.1016/s2215-0366(20)30078-x]

19. Kuang Y, Shen M, Wang Q, Xiao Y, Lv C, Luo Y, et al. Association of outdoor activity restriction and income loss with patient-reported outcomes of psoriasis during the COVID-19 pandemic: A web-based survey. J Am Acad Dermatol 2020 Aug;83(2):670-672 [FREE Full text] [doi: 10.1016/j.jaad.2020.05.018] [Medline: 32407741]

20. Gangopadhyaya AA, Garrett AB. Unemployment, Health Insurance, and the COVID-19 Recession. SSRN Journal 2020 Apr 01:online. [doi: 10.2139/ssrn.3568489]

21. Woolhandler S, Himmelstein DU. Intersecting U.S. Epidemics: COVID-19 and Lack of Health Insurance. Ann Intern Med $2020 \mathrm{Jul}$ 07;173(1):63-64 [FREE Full text] [doi: 10.7326/M20-1491] [Medline: $\underline{\text { 32259195] }}$

22. Liu S, Yang L, Zhang C, Xiang Y, Liu Z, Hu S, et al. Online mental health services in China during the COVID-19 outbreak. Lancet Psychiatry 2020 Apr;7(4):e17-e18 [FREE Full text] [doi: 10.1016/S2215-0366(20)30077-8] [Medline: 32085841]

23. Lurie N, Carr BG. The Role of Telehealth in the Medical Response to Disasters. JAMA Intern Med 2018 Jun 01;178(6):745-746. [doi: 10.1001/jamainternmed.2018.1314] [Medline: 29710200]

24. Hollander JE, Carr BG. Virtually Perfect? Telemedicine for Covid-19. N Engl J Med 2020 Apr 30;382(18):1679-1681. [doi: 10.1056/NEJMp2003539] [Medline: 32160451]

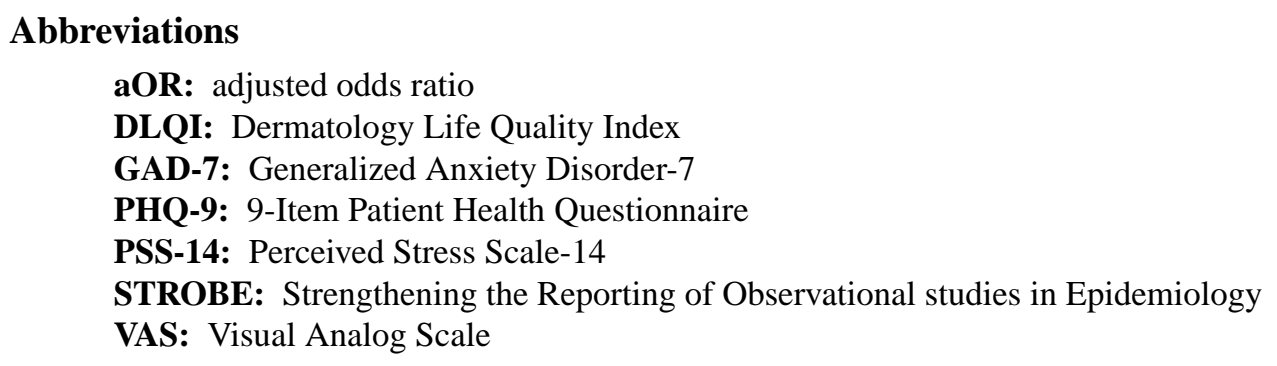


Edited by G Eysenbach; submitted 07.07.20; peer-reviewed by $Y$ Yu, Y Luo; comments to author 22.07.20; revised version received 06.08.20; accepted 10.08.20; published 11.09.20

Please cite as:

Guo Y, Shen M, Zhang X, Xiao Y, Zhao S, Yin M, Bu W, Wang Y, Chen X, Su J

Association of Socioeconomic Changes due to the COVID-19 Pandemic With Health Outcomes in Patients With Skin Diseases: Cross-Sectional Survey Study

J Med Internet Res 2020;22(9):e22288

URL: http://www.jmir.org/2020/9/e22288/

doi: $10.2196 / 22288$

PMID: $\underline{32845850}$

(C) Yeye Guo, Minxue Shen, Xu Zhang, Yi Xiao, Shuang Zhao, Mingzhu Yin, Wenbo Bu, Yan Wang, Xiang Chen, Juan Su. Originally published in the Journal of Medical Internet Research (http://www.jmir.org), 11.09.2020. This is an open-access article distributed under the terms of the Creative Commons Attribution License (https://creativecommons.org/licenses/by/4.0/), which permits unrestricted use, distribution, and reproduction in any medium, provided the original work, first published in the Journal of Medical Internet Research, is properly cited. The complete bibliographic information, a link to the original publication on http://www.jmir.org/, as well as this copyright and license information must be included. 